\title{
Cervical cancer detection method using an improved cellular neural network (CNN) algorithm
}

\author{
Azian Azamimi Abdullah ${ }^{1}$, Aafion Fonetta Dickson Giong ${ }^{2}$, Nik Adilah Hanin Zahri ${ }^{3}$ \\ ${ }^{1,2}$ School of Mechatronic Engineering, Universiti Malaysia Perlis, Malaysia \\ ${ }^{3}$ School of Computer and Communication Engineering, Universiti Malaysia Perlis, Malaysia
}

\begin{tabular}{l} 
Article Info \\
\hline Article history: \\
Received Sep 25, 2018 \\
Revised Nov 26, 2018 \\
Accepted Dec 8, 2018 \\
\hline Keywords: \\
Cellular neural network \\
Cervical cancer \\
Image processing \\
MATLAB \\
Pap smear
\end{tabular}

Article Info

Article history:

Received Sep 25, 2018

Revised Nov 26, 2018

Keywords

Cellular neural network

Image processin

Pap smear

\begin{abstract}
Cervical cancer is the second most common in Malaysia and the fourth frequent cancer among women in worldwide. Pap smear test is often ignored although it is actually useful, beneficial and essential as screening tool for cervical cancer. However, Pap smear images have low sensitivity as well as specificity. Therefore, it is difficult to determine whether the abnormal cells are cancerous or not. Recently, computer-based algorithms are widely used in cervical cancer screening. In this study, an improved cellular neural network $(\mathrm{CNN})$ algorithm is proposed as the solution to detect the cancerous cells in real-time by undergoing the image processing of Pap smear images. A few templates are combined and modified to form an ideal CNN algorithm to detect the cancerous cells in total of 115 Pap smear images. A MATLAB based CNN is developed for an automated detection of cervix cancerous cells where the templates segmented the nucleus of the cells. From the simulation results, our proposed $\mathrm{CNN}$ algorithm can detect the cervix cancer cells automatically with more than $88 \%$ accuracy.
\end{abstract}

Copyright (C) 2019 Institute of Advanced Engineering and Science. All rights reserved.

\section{Corresponding Author:}

Azian Azamimi Abdullah, School of Mechatronic Engineering, Universiti Malaysia Perlis, Pauh Putra Campus, 02600 Arau, Perlis, Malaysia.

Email: azamimi@unimap.edu.my

\section{INTRODUCTION}

Cervical cancer is a cancer of the cervix, which is commonly caused by a virus named Human Papillomavirus (HPV) [1]. The virus can damage cells in the cervix, namely, squamous cells and glandular cells that may develop into squamous cell carcinoma (cancer of the squamous cells) and adenocarcinoma (cancer of the glandular cells), respectively. Based on World Health Organization (WHO), cervical cancer is the fourth most frequent cancer in women after breast, colorectal, and lung cancers with an estimated 530,000 new cases in 2012 representing 7.9\% of all female cancers [2]. Approximately 90\% the 270,000 deaths from cervical cancer in 2015 occurred in low and middle-income countries [3]. Meanwhile, in Malaysia, the cervix cancer was the second common cancer among women, behind the breast cancer [4]. Rate of incidence of cervical cancer increased after reaching 30 years of age and peaks from 65 - 69 years old. In Malaysian statistic, out of all the races, Indian women possess the highest occurrence subsequently behind is Chinese followed by Malay. 10.3 per 100,000 populations are the ASR for Indian females [5].

Pap smear screening test is the method used to look for pre-cancers, which are the cells that changed on the cervix that might become cervical cancer if they are not treated appropriately. The screening for cervical cancer will detect precursor lesions therefore allow early and potentially less invasive treatment that what is required for diseases that cause the symptoms. Pap smear test is a simple, effective and cheap, but it is not a disease specific test, which has low sensitivity and specificity [6]. Another disadvantage of Pap smear is that an abnormal Pap smear result does not always indicate cancer. Cells sometimes appear abnormal but 
they are not cancerous. Therefore, it is difficult to determine whether the abnormal cells are cancerous or not. With these limitations, the cancerous cells will be hard to detect and it will take a longer time for the radiologist or doctor and other medical personnel to determine the existence of cancerous cells and consequently will lead to the spreading of it to the surrounding cells. Recently, there are many methods utilizing computer algorithms for detecting the cancerous cells in cervix [7]-[12]. These methods employed several image processing techniques with classification algorithms to diagnose cervical cancer. Basically, there were four stages of the computer system including image enhancement, features extraction, feature selection, and classification. However, there are still limitations in automated detection without undergoing these four stages. On the other hand, cellular neural networks (CNN) are a parallel computing paradigm similar to neural networks, with the difference that communication is allowed between neighbouring units only. Cellular neural network (CNN) is a network, which is locally connected [13]. The output of the neuron is connected with the input of every neuron in $3 \times 3$ neighborhoods. Likewise, the inputs of neurons are connected only to output of every neuron in its $3 \times 3$ neighborhood. In image processing, CNN basically will do the mapping or transformation of an input image to its corresponding output image. For instance, any input images in analogue form can be transformed into a specific output image, which its value is in binary. In CNN, feedback connections are present and each of the neuron of the network applied the similar processing function. Cellular Neural Network uses these three main operations namely, filtering, segmentation and edge detection.

CANDY Software is an application development and environment toolkit based CNN for windows [14]. It is also known as Visual Mouse Software Platform or VisMouse [15]. Few templates were explored and considered such as blue channel extraction template, contrast enhancement template, median filter template, binary edge detection template and hollow-concave template. $\mathrm{CNN}$ is chosen for the method of detection in medical image processing due to its efficiency in pattern recognition and image processing [16]-[20]. CNN algorithm is also applied in memristor [21]-[23], srobotics [24], ditributed network [25] and raindrop detection [26]. Hence, in this study, a new detection method by using CNN algorithm will be used to detect the cancerous cervical cells in a shorter time.

\section{RESEARCH METHOD}

The most important part in this project is designing the template and development of the algorithm to detect the cervix cancer by using Pap smear images. Prior to the development of the improved algorithm, the characteristics of each images need to be analyzed and CNN need to be understood fully. To design a template, the initial state, boundary condition, feedback and threshold value has to be studied beforehand.

A total of 13 images were collected from HUSM Kubang Kerian and another 102 images retrieved from Pap smear image database. A total of 115 images were used to simulate our developed MATLAB based CNN simulator. This MATLAB based CNN simulator is a user-friendly software. The output image will be shown at the end of the transients. This improved MATLAB CNN simulator is used for Pap smear images processing and to detect the cancerous cells. Flow chart of the algorithm for cervix cancer cell detection is shown in Figure 1.

The Graphical User Interface, which is in MATLAB, is utilized for the purpose of development of the CNN Simulator to detect the cervical cancer in the Pap smear image. These templates, which are designed for the detection of cervical cancer, are developed to reduce the consuming time to obtain the results. The process of using the MATLAB based CNN Simulator is easy by simply load the input image, run the image and the final simulated output image will be displayed at the end of the templates. The GUI of the improved Matlab CNN simulator is shown in Figure 2.

\subsection{Template Design}

Template 1 is a Blue Channel Extraction template that can be found in CNN library [27]. The template set contained of A (feedback), B (control) and Z (bias) template and they are shown as below:

Template $\mathrm{A}=$\begin{tabular}{|l|l|l|}
\hline 0 & 0 & 0 \\
\hline 0 & 1 & 0 \\
\hline 0 & 0 & 0 \\
\hline
\end{tabular} Template $\mathrm{B}=$

\begin{tabular}{|l|l|l|}
\hline 2 & -2 & 2 \\
\hline 0 & 0 & 0 \\
\hline 2 & -2 & 2 \\
\hline
\end{tabular}

Bias, $Z=-0.7$

The template is applied in the Matlab CNN simulator and the result is shown as Figure 3. 


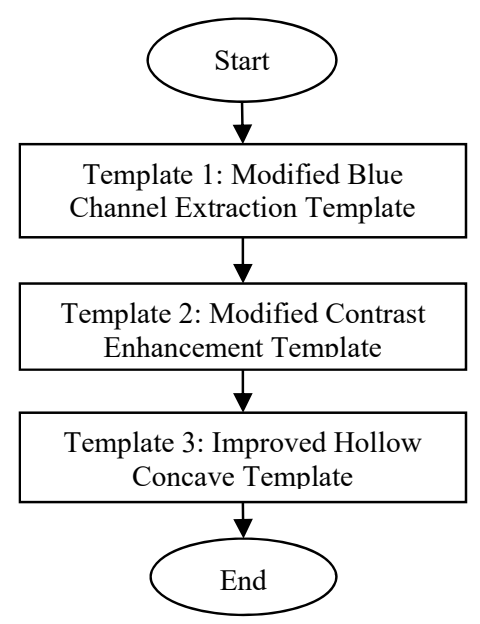

Figure 1. Flow chart of $\mathrm{CNN}$ algorithm for cervix cancer detection

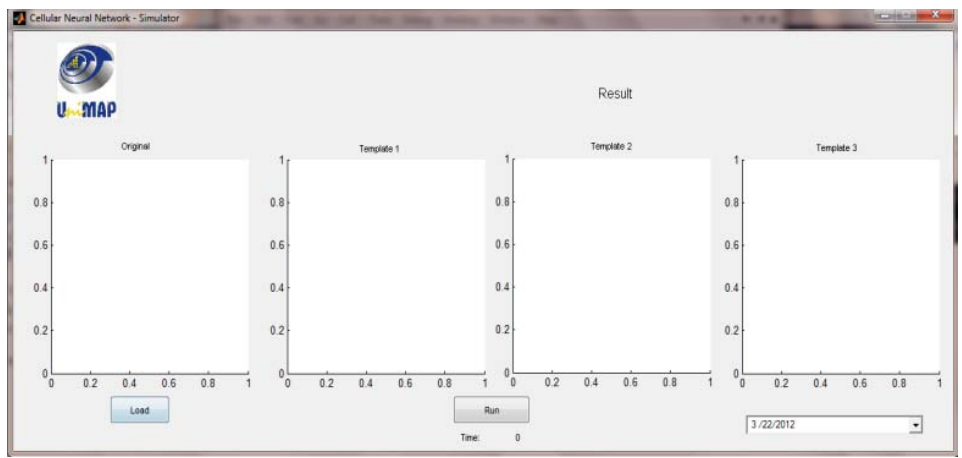

Figure 2. GUI of Improved Matlab CNN Simulator.

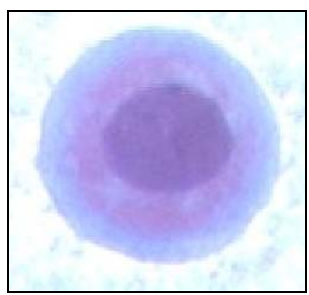

(a) Original Image

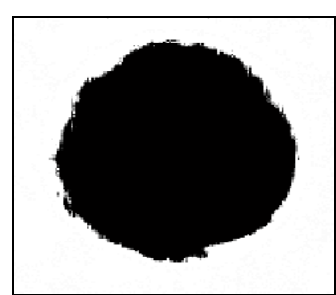

(b) Simulated Image

Figure 3. Original and simulated image using Blue Channel Extraction template.

From Figure 3, the simulated result cannot show the actual nucleus of the cell. To obtain the desired image, a modification on the template is made and is shown below. The modified template produced the result shown in Figure 4.

Template $\mathrm{A}=$

\begin{tabular}{|l|l|l|}
\hline 1 & 1 & 1 \\
\hline 1 & -7.5 & 1 \\
\hline 1 & 1 & 1 \\
\hline
\end{tabular}

Template $\mathrm{B}=$

\begin{tabular}{|l|l|l|}
\hline 2 & -2 & 2 \\
\hline 0 & -2 & 0 \\
\hline 2 & -2 & 2 \\
\hline
\end{tabular}


Bias, $Z=1.5$

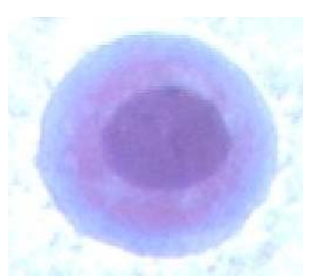

(a) Original image

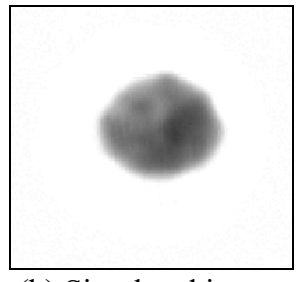

(b) Simulated image

Figure 4. Original and simulated image using modified Blue Channel Extraction template.

Figure 4 shows that the modified template is able to filter out the nucleus of the cell. The unwanted background is filtered out and hence the output image is more presentable for the detection of abnormal cells. Next, Template 2 is used, which is the Contrast Enhancement template in order to proceed with the next step. The template is shown below and the simulated result is shown in Figure 5.

Template $\mathrm{A}=$

Template $\mathrm{B}=$

\begin{tabular}{|l|l|l|}
\hline 0 & 0.25 & 0 \\
\hline 0 & 0 & 0.2 \\
\hline 0 & 0.25 & 0 \\
\hline \hline 0 & -1 & 0 \\
\hline-1 & 4 & -1 \\
\hline 0 & -1 & 0 \\
\hline
\end{tabular}

Bias, $Z=-0.7$

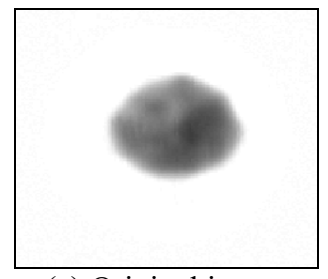

(a) Original image

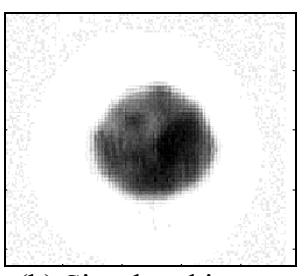

(b) Simulated image

Figure 5. Original and simulated image using Contrast Enhancement template.

From Figure 5, the simulated result shows an enhancement of the darkest area of the original image. However, the unnecessary background reappears and therefore the template needs to be modified as shown below:

Template $\mathrm{A}=$

Template $\mathrm{B}=$

Bias, $\mathrm{Z}=0.2$

After applying the modified Contrast Enhancement template, it is observed that only the nucleus appeared in the simulated image as shown in Figure 6. By adjusting the simulation time and the template, the output image shows only the darkest area of the previous image. For the final step, Template 3, which is the Hollow Concave template, is used in order to get the final result. The template is shown below: 


\begin{tabular}{|l|l|l|}
\hline 0.5 & 0.5 & 0.5 \\
\hline 0.5 & 2 & 0.5 \\
\hline 0.5 & 0.5 & 0.5 \\
\hline
\end{tabular}

Template $\mathrm{A}=$

\begin{tabular}{|l|l|l|}
\hline 0 & 0 & 0 \\
\hline 0 & 2 & 0 \\
\hline 0 & 0 & 0 \\
\hline
\end{tabular}

Template $\mathrm{B}=$

Bias, $\mathrm{Z}=3.25$

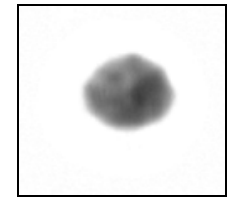

(a) Original image

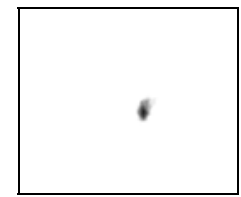

(b) Simulated image

Figure 6. Original and simulated image using modified Contrast Enhancement template

The original template and the simulated result from Template 3 are shown in Figure 7.

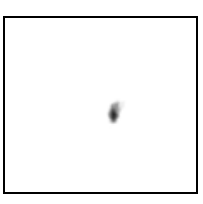

(a) Original image

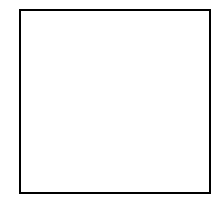

(b) Simulated image

Figure 7. Original and simulated image using Hollow Concave template

The

Concave

display a small

Hollow

shown below:

Template $\mathrm{A}=$

\begin{tabular}{|l|l|l|}
\hline 0.75 & 0.75 & 0.75 \\
\hline 0.75 & 5 & 0.75 \\
\hline 0.75 & 0.75 & 0.75 \\
\hline
\end{tabular}

simulated image in Figure 7 after applying the original Hollow template does not show the desirable output. It is supposed to nucleus that indicates the abnormal cell. Hence, and improved Concave template is developed for the detection of abnormal cell as

\begin{tabular}{|l|l|l|}
\hline 0 & 0 & 0 \\
\hline 0 & 5 & 0 \\
\hline 0 & 0 & 0 \\
\hline
\end{tabular}

Template $\mathrm{B}=$

Bias, $\mathrm{Z}=3.25$

Figure 8 .

The output of the image after applying the new modified Hollow Concave template is shown in 


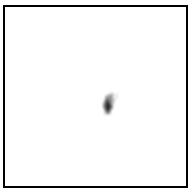

(a) Original image

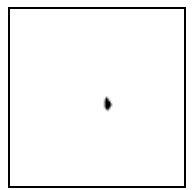

(b) Simulated image

Figure 8. Original and simulated image using modified Hollow Concave template

Figure 8 shows a clean image without unnecessary background and noises. The final output after applying the modified Hollow Concave template shows the small black nucleus that represents the abnormal cell.

\section{RESULTS AND ANALYSIS}

From this study, the information obtained from the simulation is the preliminary result, which can be used by the medical personnel for recommendation and final decision regarding further treatment of the patients, if an abnormal result is obtained. Medical personnel can decide whether the cells are cancerous or non-cancerous. The MATLAB based CNN can also be used by the medical practitioners or students as their guidelines in determining cancerous cells and as a learning purpose. Interpreting the images became easier and can reduce the consumed time.

The cancerous cells are invincible throughout the life until women finally decide on Pap Smear Test. To decide on an abnormal or normal cell, this automated cervix cancer cells detection which implementing the CNN algorithm can be used. The templates were modified and improved in order to be in sync with the Pap smear images given. The observation is based on the size of the nucleus and the number of multiplied cells in an image. As for this study, the nucleus is set as the parameters to be observed, and after the simulation, the white area represents the nucleus and black area represents the rest of the cell.

The simulation result in detecting cancerous cells in Pap smear image are shown in Figure 9 and Figure 10 for the example of abnormal cells, respectively. Figure 11 and Figure 12 show the simulation result of Pap smear image for the example of normal cells. It is observed that for abnormal cells, the black dot indicating the nucleus will appear at the final stage. Unlike for normal cells, the black dot (nucleus) will disappear after Template 3.
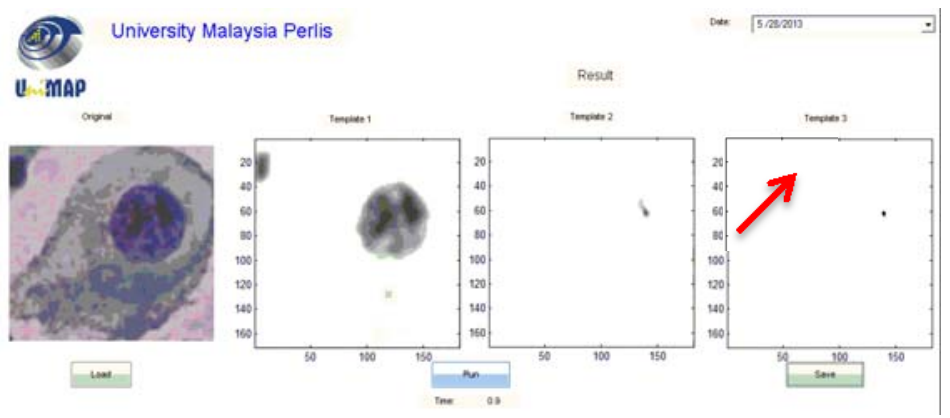

Figure 10. Abnormal cells of Pap smear image (Sample 1)

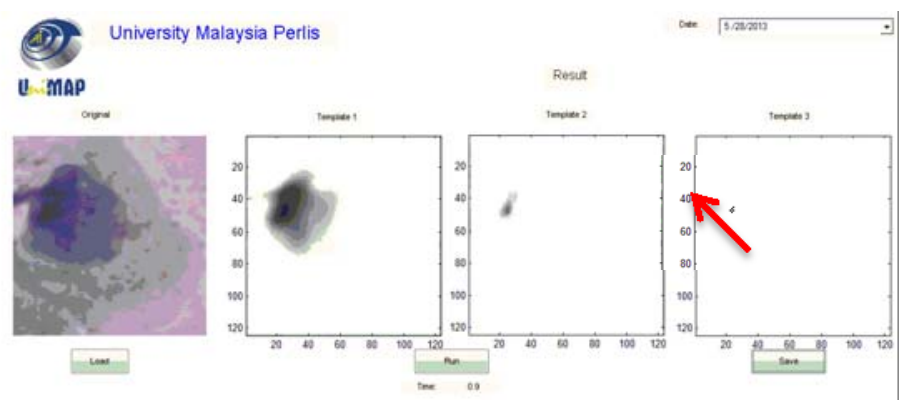

Cervical cancer detection method using an improved cellular neural network... (Azian Azamimi Abdullah) 
Figure 11. Abnormal cells of Pap smear image (Sample 2)

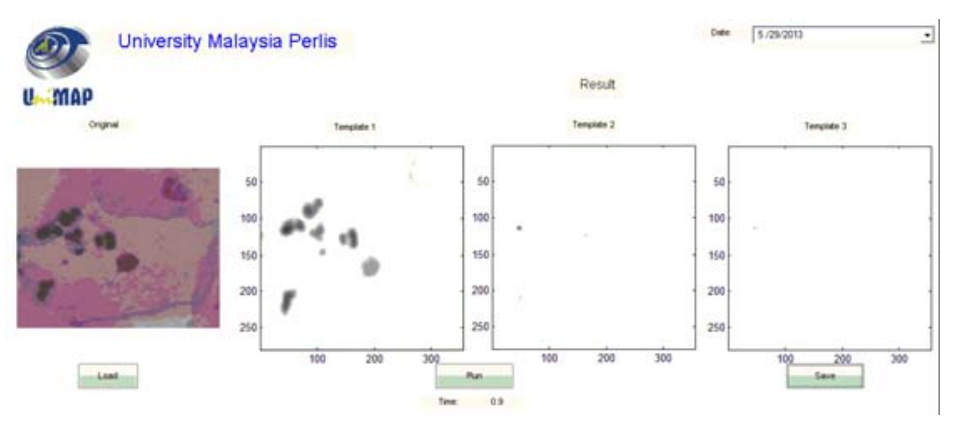

Figure 12. Normal cells of Pap smear image (Sample 3)

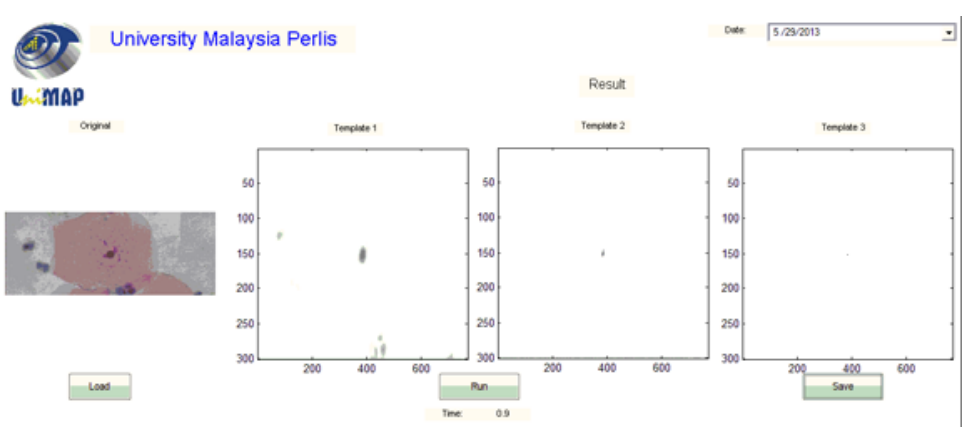

Figure 13. Normal cells of Pap smear image (Sample 4).

The percentage for each type of abnormal cells is shown in Table 1 while Table 2 shows the percentage of accuracy for each type of the normal cells. From Table 1, it can be concluded that the overall accuracy for the 65 of abnormal images with 59 detected abnormalities is $90.77 \%$. The accuracy is considered high for the detection of abnormal cervical cells. From Table 2, it is observed that 43 non-cancerous Pap smear images are correctly detected over total of 50 images and the accuracy is $85.54 \%$. The limited number of noncancerous images is the main factor why the accuracy is quite low compared to the cancerous images.

Table 1. Percentage of accuracy for each cell (Cancerous)

\begin{tabular}{llll}
\hline Type of cells & Number of detected cells & Total cells simulated & Percentage of accuracy (\%) \\
\hline Light Dysplastic & 16 & 18 & 88.89 \\
Moderate Dysplastic & 15 & 16 & 93.75 \\
Severe Dysplastic & 12 & 13 & 92.31 \\
Carcinoma In Situ & 16 & 18 & 88.89 \\
Total & 59 & 65 & 90.77 \\
\hline
\end{tabular}

Table 2. Percentage of accuracy for each cell (Non-cancerous)

\begin{tabular}{lccc}
\hline Type of cells & $\begin{array}{l}\text { Number of } \\
\text { undetected } \\
\text { cells }\end{array}$ & $\begin{array}{l}\text { Total cells } \\
\text { simulated }\end{array}$ & $\begin{array}{l}\text { Percentage of } \\
\text { accuracy (\%) }\end{array}$ \\
\hline $\begin{array}{l}\text { Normal } \\
\text { Superficial }\end{array}$ & 19 & 22 & 86.36 \\
$\begin{array}{l}\text { Normal } \\
\text { Intermediate }\end{array}$ & 14 & 15 & 93.33 \\
$\begin{array}{l}\text { Normal } \\
\text { Columnar }\end{array}$ & 10 & 13 & 76.92 \\
\hline Total & 43 & 50 & 85.54
\end{tabular}




\section{CONCLUSION}

CNN is frequently used in image processing, high-speed signal processing, video signal processing, biological visions and pattern recognition. $\mathrm{CNN}$ is implemented in this study particularly to detect the cervix cancer cells automatically by designing the templates and fully utilizing the function of MATLAB software. The templates are designed after considering essential parameters such as initial state, boundary condition, pixel value, control template, feedback template and threshold value. Based on the simulation results, 59 abnormal images were detected correctly, out of total 65 images. The obtained accuracy was $90.77 \%$. For the non-cancerous images, 43 images were detected as normal cells, out of total 50 images with accuracy of $85.54 \%$. For future improvement, more images need to be simulated under this MATLAB based CNN simulator for more accurate and precise results. Lack of images hinders the precision of the designed template. Every image has different composition, brightness and intensity. In order to fulfill and achieve the stability of the newly designed templates, more images needed for the simulation and analysis. In the future, classification can be made where the calculation of the size of the nucleus can be preceded for a high accuracy and precision.

\section{ACKNOWLEDGEMENTS}

This work was funded by Universiti Malaysia Perlis (UniMAP) research grant 9009-00053.

\section{REFERENCES}

[1] Y. Jusman, S. C. Ng, and N. A. Abu Osman, "Intelligent screening systems for cervical cancer," Scientific World Journal, vol. 2014. 2014

[2] J. Ferlay, I. Soerjomataram, R. Dikshit, S. Eser, C. Mathers, M. Rebelo, D. M. Parkin, D. Forman, and F. Bray, "Cancer incidence and mortality worldwide," IARC CancerBase No. 11GLOBOCAN 2012, 2013.

[3] WHO and ICO, "Human Papillomavirus and Related Diseases Report - WORLD," HPV Inf. Cent., no. Albania, pp. 1-138, 2014.

[4] S. Zaridah, “A review of cervical cancer research in Malaysia,” Med. J. Malaysia, vol. 69, pp. 33-41, 2014.

[5] ICO HPV Information Centre, "Human Papillomavirus and Related Diseases Report WORLD,” 2017.

[6] E. Njoroge, S. R. Alty, M. R. Gani, and M. Alkatib, "Classification of cervical cancer cells using FTIR data.," Annu. Int. Conf. IEEE Eng. Med. Biol. Soc., vol. 1, pp. 5338-41, 2006.

[7] G. Rigon, C. Vallone, A. Starita, M. Flavio, M. Vismara, P. Ialongo, L. Putignani, and F. Signore, "Diagnostic Accuracy of MRI in Primary Cervical Cancer," Open J. Radiol., vol. 2, pp. 14-21, 2012.

[8] S. N. Sulaiman, N. A. Mat-Isa, N. H. Othman, and F. Ahmad, "Improvement of features extraction process and classification of Cervical cancer for the NeuralPap system," in Procedia Computer Science, 2015, vol. 60, no. 1, pp. 750 759.

[9] M. Zhao, A. Wu, J. Song, X. Sun, and N. Dong, "Automatic screening of cervical cells using block image processing," Biomed. Eng. Online, vol. 15, no. 1, 2016.

[10] P. Sukumar and R. K. Gnanamurthy, "Computer aided screening of cervical cancer using random forest classifier,” Res. J. Pharm. Biol. Chem. Sci., vol. 7, no. 1, 2016.

[11] N. A. Obukhova, A. A. Motyko, U. Kang, S.-J. Bae, and D.-S. Lee, "Automated image analysis in multispectral system for cervical cancer diagnostic," Conf. Open Innov. Assoc. Fruct, vol. 2017-April, 2017.

[12] L. Wei, Q. Gan, and T. Ji, "Cervical cancer histology image identification method based on texture and lesion area features," Comput. Assist. Surg., vol. 22, pp. 186-199, 2017.

[13] L. O. Chua and L. Yang, "Cellular neural networks: theory," IEEE Trans. Circuits Syst., vol. 35, no. 10, pp. $1257-1272,1988$.

[14] L. O. Chua and T. Roska, Cellular neural networks and visual computing: foundation and applications. 2002.

[15] P. Szolgay, A. ZarAndy, S. Zold, T. Roska, P. Foldesy, L. Kek, T. Kozek, K. Laszlo, I. Petras, C. Rekeczky, I. Szatmari, and D. Balya, "The computational infrastructure for cellular visual microprocessors," Proc. 7th Int. Conf. Microelectron. Neural, Fuzzy Bio-Inspired Syst. MicroNeuro 1999, pp. 54-60, 1999.

[16] A. A. Abdullah and H. Mohamaddiah, "Development of cellular neural network algorithm for detecting lung cancer symptoms," Biomedical Engineering and Sciences IECBES 2010 IEEE EMBS Conference on. IEEE, pp. 138$143,2010$.

[17] A. A. Abdullah, B. S. Chize, and Y. Nishio, "Implementation of an improved cellular neural network algorithm for brain tumor detection," in 2012 International Conference on Biomedical Engineering (ICoBE), 2012, pp. 611-615.

[18] S. C. Ling, A. A. Abdullah, and W. K. W. Ahmad, "Design of an automated breast cancer masses detection in mammogram using Cellular Neural Network (CNN) algorithm,” Adv. Sci. Lett., vol. 20, no. 1, pp. 254-258, 2014.

[19] R. Rouhi, M. Jafari, S. Kasaei, and P. Keshavarzian, "Benign and malignant breast tumors classification based on region growing and CNN segmentation," Expert Syst. Appl., vol. 42, no. 3, pp. 990-1002, 2015.

[20] A. A. Abdullah, N. M. Posdzi, and Y. Nishio, "Preliminary study of pneumonia symptoms detection method using Cellular Neural Network," International Conference on Electrical Control and Computer Engineering 2011 InECCE. IEEE, pp. 497-500, 2011.

Cervical cancer detection method using an improved cellular neural network... (Azian Azamimi Abdullah) 
[21] S. Duan, X. Hu, L. Wang, S. Gao, and C. Li, "Hybrid memristor/RTD structure-based cellular neural networks with applications in image processing," Neural Comput. Appl., 2013.

[22] X. Hu, G. Feng, S. Duan, and L. Liu, "A memristive multilayer cellular neural network with applications to image processing,” IEEE Trans. Neural Networks Learn. Syst., vol. 28, no. 8, pp. 1889-1901, 2017.

[23] M. Di Marco, M. Forti, and L. Pancioni, "Memristor standard cellular neural networks computing in the fluxcharge domain," Neural Networks, vol. 93, pp. 152-164, 2017.

[24] Y. Zhong, B. Shirinzadeh, and X. Yuan, "Optimal robot path planning with cellular neural network," Int. J. Intell. Mechatronics Robot., vol. 1, no. 1, pp. 18-37, 2011.

[25] K. Xie, Y. Yang, Y. Xin, and G. Xia, "Cellular Neural Network-Based Methods for Distributed Network Intrusion Detection," vol. 2015, 2015.

[26] F. Al Machot, M. Ali, A. Haj Mosa, C. Schwarzlmüller, M. Gutmann, and K. Kyamakya, "Real-time raindrop detection based on cellular neural networks for ADAS," J. Real-Time Image Process., pp. 1-13, 2016.

[27] K. Karacs, Á. Zarándy, P. Szolgay, C. Rekeczky, L-Kék, V. Szabó, G. Pazienza, and T. Roska, "Software Library for Cellular Wave Computing Engines in an era of kilo-processor chips," 2010

\section{BIOGRAPHIES OF AUTHORS}
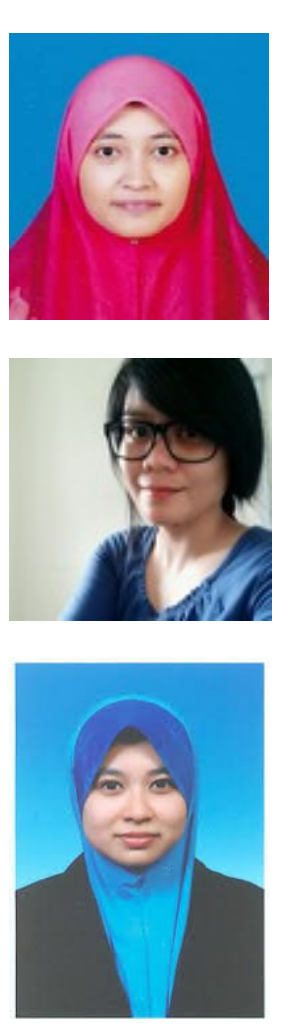

Dr Azian Azamimi Abdullah has obtained her degree and master's degree from The University of Tokushima, Japan in Electrical and Electronic Engineering. She also has completed her doctorate degree from Nara Institute of Science and Technology (NAIST), Japan in 2017. Previously, she worked as an engineer at Toshiba Electronics and currently serves as a senior lecturer at University Malaysia Perlis. Her research interests are bioinformatics, artificial intelligence, big data and machine learning.

Mrs Aafion Fonetta Dickson Giong has obtained her degree from Universiti Malaysia Perlis in Biomedical Electronic Engineering programme.

Dr Nik Adilah Hanin Zahri obtained her degree and master's degree in Computer Science and Media from University of Yamanashi, Japan. She also has completed her doctorate degree from the same university in Medical Engineering (Human Environment Medical Engineering).

Currently, she works as senior lecturer at School of Computer and Communication Engineering in Universiti Malaysia Perlis. 